\title{
Case Study: Potential Violation Of The Employee Assistance Program (EAP)
}

John J. Lucas, Purdue University Calumet, USA

Stephanie Clute, Metropolitan State-University of Denver, USA

\begin{abstract}
This Human Resource Management case focuses on a potential violation of a company's Employee Assistance Program (EAP) and the appropriate procedure to address this issue. This case is based upon an actual event that occurred at a production plant of a Fortune 500 company. The case study can be used for any undergraduate or graduate level human resource management class. It is designed to be conducted as a group assignment or general class discussion within one class hour.
\end{abstract}

Keywords: Employee Assistance Programs; Human Resource Management

\section{BACKGROUND}

n mid-October, Willie, a mechanical maintenance worker and also a member of the International Brotherhood of Electrical Workers (IBEW), was a no-call, no-show at a production plant for the ABC Company. A couple of days later, Willie called his immediate supervisor and explained that he had
entered a drug rehabilitation center because his drug dependency was destroying his life and his ability to perform his job responsibilities at the production plant. After twenty-eight days in the drug rehabilitation center, he met with his supervisor and a representative of the Human Resource department to address the appropriate disciplinary problems regarding his no-call, no-show. He was given three days without pay as discipline, in accordance with company policy. Willie also signed an employment contract agreeing to be randomly tested for drugs for at least a year or longer, based upon the recommendation of the Medical Review Officer (MRO). Thus, he was obliged to remain drug-free as a condition of employment with the ABC Company. Any violation of his random drug test, such as a positive test for drugs, would result in his immediate termination of employment with the company.

In mid-December, he was requested, by the medical department of the company, to submit to a random drug test. The drug test was negative and he returned to work at the production plant. In March of the following year, Willie was again requested to submit to another random drug test which also was negative for drugs. In June, he was requested to submit to a random drug test but was unable to provide a urine specimen to be tested for drugs, even after seven hours at the company's medical facility. It was decided by the corporate Labor Relations department that Willie be released to go home instead of paying overtime to provide a urine specimen. Hence, Willie went home after his normal shift ended, without providing a urine specimen as requested by the Medical department.

A few weeks later, the Medical department requested that Willie provide another urine specimen for drugs. Once again, Willie was unable to provide a urine specimen after several attempts during his basic work shift. However, this time the HR professional informed him that his work assignment was to provide a urine specimen to be tested for drugs and the company would be paying him overtime until he gave a urine specimen. From 3:30pm until 6:30pm, the HR professional accompanied Willie and he still could not provide a urine specimen. The HR professional then drove Willie to a nearby medical facility where a hired male nurse would stay with Willie until a specimen was rendered. At 2:30 the next morning, the HR professional received a phone call from the male nurse that Willie had finally submitted a urine specimen to be tested for drugs. Thus, it took over eighteen hours for Willie to provide a urine specimen. 
A few days later, the MRO of the company confirmed to the HR professional that the drug test was positive for drugs. With the confirmation of a positive drug test, Willie was terminated for violation of the drug policy at the $\mathrm{ABC}$ Company.

\section{UNION'S POSITION}

Although the union does not condone the usage of drugs by any of its union members, the company has unilaterally implemented a drug policy. Willie was a valued employee who knew that he had become dependent on an illegal drug which was destroying his family life as well as his ability to perform his job as a mechanical maintenance worker at the plant. He had a "little slip" in his attempt to remain drug-free. Thus, Willie should be given another opportunity to enter a drug rehabilitation center. If he is successful at the drug center and remained drug-free during his stay, he should be returned to his job at the production plant.

\section{COMPANY'S POSITION}

The company has an obligation to provide a drug-free work environment for its employees. In this case, Willie was clearly attempting to evade providing a urine specimen because he knew that the results of the drug test would be positive. Additionally, he also was fully aware that he had signed an employment agreement that he would remain drug-free or he would be immediately terminated from the company. The drug test was confirmed to be positive and the termination of Willie was for "just cause", as identified in the labor agreement.

\section{QUESTIONS FOR THE CASE STUDY}

1. Was the action, by the company, to terminate the mechanical maintenance worker for violation of the EAP correct?

2. Should the mechanical maintenance worker been given another opportunity to enter a drug rehabilitation center?

3. Would it be probable for an employee to return to his position of employment under the condition of attending an outpatient treatment program?

4. What if the drug test result had been diluted (tested neither positive nor negative); what is the appropriate action that should be taken by the company?

5. What possible recourse, if any, is available to the mechanical maintenance employee if he regarded the discharge to which he was subjected as excessive or without "just cause?"

6. Is the company required to negotiate a drug/alcohol policy with the union?

7. Do you agree with the Labor Relations department's directive that he should not have been paid overtime to provide a urine sample?

8. Are employees, who successfully completed a rehabilitation treatment program, covered by the Americans with Disabilities Act (ADA)?

\section{AUTHOR INFORMATION}

Dr. John J. Lucas is a Professor at Purdue University Calumet and teaches a variety of human resource management courses. He earned his Master of Science in Industrial Relations (MSIR) and Ph.D. degrees from Loyola University Chicago. His research interests are in the areas of labor relations, employee benefits, and health education. He is also a graduate of Purdue University Calumet. E-mail: jlucas@purduecal.edu (Corresponding author)

Ms. Stephanie D. Clute is a senior undergraduate student at Metropolitan State University of Denver majoring in management and psychology with an emphasis on human resource management. 


\section{INSTRUCTOR'S NOTES}

This case provides an interesting examination of the EAP at a company and the potential violation of it with a positive random drug test. According to the National Survey on Drug Use and Health (NSDUH), 23.2 million persons age 12 or older needed treatment for an illicit drug or alcohol use problem. There is no single treatment for an individual, but effective treatment addresses the multiple needs of the individual, not just his or her drug abuse. In many cases, three months of treatment is considered to be sufficient and the standard length of treatment is one to three months. Short-term treatment programs can range from 30 to 60 days while long-term treatment programs range from 30 to 90 days. Additionally, Treatment in Therapeutic Communities (TC), where peer influence and social responsibility is important in a community setting, is anywhere from 18 to 24 months. The critical element is for the individual to remain in treatment for an adequate period of time in the selected drug rehabilitation program. Unfortunately, most people relapse 120 days after being released from a drug rehabilitation program, partially due to lack of follow-up. This, of course, raises questions about the responsibilities of EAP programs, of companies that offer them, of employees who are directed to them, and of the punishment administered by companies in the cases of employees who my not fulfill their obligations because of lack of followup. 
NOTES 